\title{
An Agent based Personalized Intelligent e-learning
}

\author{
Axita Shah \\ AES Institute of Computer Studies, \\ Ahmedabad, India
}

\author{
Sonal Jain \\ GLS Institute of Computer Technology, \\ Ahmedabad, India
}

\begin{abstract}
Education is foundation of any modern society. Self Discovery is a key to an individual's education success. Self Discovery learning is the ability of an individual to learn through personal experience and natural exploration. Online Discovery learning tends to be learner-driven and learner-initiated. Digital repository on web is supportive for online discovery learning. In recent era, availability of infrastructure, flexibility of time, learning resources and their means of sharing has increased adaptability of World Wide Web to learn and attain knowledge to a great extent. However, most of the e-learners find difficulty to select location specific, relevant and significant tutorial on the web. Search engines results pages are not based on the interest, knowledge level and literacy rate of learner. More amount of time spent on searching and filtering and comparatively less time is devoted in actual learning. This paper proposes an agent based personalized intelligent e-learning model. The essence of personalized search engine is to save learner's time to re-rank future result list. This Model uses multiple agents which delivers personalized SERP (Search Engine Results Page) and is more suited for personalization of web pages based on learner's query expanded to manifold queries with novel concept of keyword research and discover knowledge using browser's behaviour. The proposed model uses web usage mining techniques to discover the knowledge of learner.
\end{abstract}

\section{INTRODUCTION}

Data and the information available on the web are evolving huge. Some of the data are useful while some are not. Search engine results too many pages that might not be of the user's interest. User spends lots of time in searching data and information on the rich web. Usage of online material is playing an important role for the learners in self discovery learning process but it is difficult to find relevant pages from the web because of gigantic web pages. This paper proposes an agent based intelligent personalized e-learning model.

The objective of the model is to produce preferred, relevant and recommended personalized search which provides the result of the learner's query based on the learner' interests and preferences by re-ranking search engine result pages. Figure 1 represents an obstruct view of a model which depicts interaction between learner and Agents resulting to an Intelligent Personalized Search. Search engine is enriched with implicit feedback received from learner's browser behaviour pattern which is stored as web log history and also from explicit feedback through opinion of the learner.

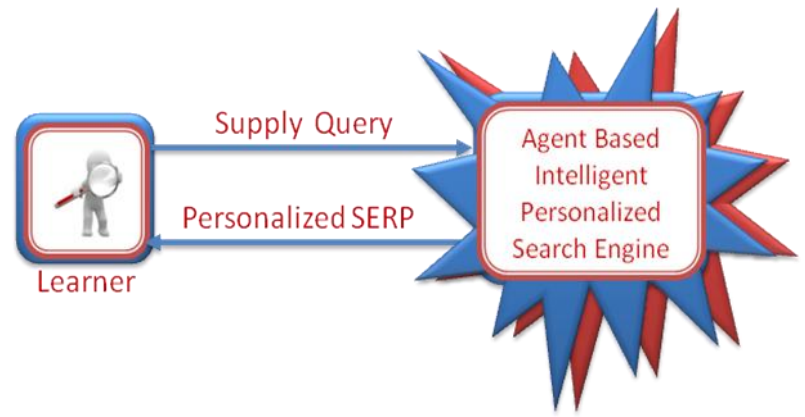

Figure-1 Obstruct representation for Agent based Intelligent Personalized Search Engine

Query provided by a learner as an input will be processed in step by step manner by multiple Agents to generate personalized reranked Search engine pages. The model includes agents like Query Expansion agent, First Tier Search Agent, Middleware Agent, Web log pre-processor Agent, Web Knowledge Discovery Agent and Opinion Agent. The following sections of the paper include related work, detailed explanation of each of the agents mentioned in the proposed model followed by conclusion and future work.

\section{RELATED RESEARCH}

Self Discovery is certainly a key to an individual's education success. Education begins from self discovery learning for everyone. Self Discovery learning is a kind of autonomous and learner's directed learning. It is the ability of an individual to learn through personal experience and natural exploration. Online Discovery learning tends to be learner-driven and learnerinitiated. Digital repository on web is supportive for online discovery learning. It may help to probe what learning sequences are most effective and why; how different learners may have their needs addressed individually [8]. To fulfill the need of individual for searching online educational resources the concept of personalization e-learning receives a great deal.

There are plenty of opportunities in research in this area of personalized e-learning. Researchers have worked using different techniques to provide personalization when learner searches online learning material on the web. Learner's searching query should be expanded to understand the user request better by identifying domain and task of user query and expanding user query using contextual information such as domain, user and task-specific preferences [1]. To improve search engine quality in a domain specific search engine, Natural language processing is used to find out the similar words which matches the query string. This does not consider user's interest but only consideration is to improve precision and recalling rate of relevant pages available on the web [21]. One of the researchers (I. Seher) has proposed the method which is based on rules for extracting the 
words in the neighbourhood of a target word, then connecting this with the surroundings of other occurrences of the same word in the text corpus [9]. To get the result of expanded Query there are plenty of search engines are available but first tier search engines like Google, Yahoo and Bing are providing full proof result compared to others [12].

Results composed from First tier search engines is gigantic. Now a day World Wide Web is used for learning due to flexibility of time, sharing of learning resources and availability of an infrastructure etc... Most of the e-learners find difficulty in selecting most relevant and significant tutorial on the web pertaining to their interest. Certain factors should be considered for filtration like domain Information, learner's profiler. Every learner is having different potential to learn from the learning material based on the different literacy rate of different states in India [15]. Research work has proposed to define personalization effectiveness based on the entropies and use it to balance the weights between the content and location facets [14]. A novel technique has been proposed to map a user query to a set of categories, which represent the user's search intention. This set of categories can serve as a context to disambiguate the words in the user's query. For example, if the category "cooking" or the category "fruit" is associated with the query "apple", then the user's intention becomes clear [5]. Category mapping can be generated from user's profile with knowledge base.

Recently there has been a growing amount of research movement on learning aspects of the personalization problem. To solve this problem various web based educators rely on human participation to collect profile information about users. This endures from the problems of the profile data getting out of date as user preferences change over time. Research has been done to provide several techniques in which user preferences are automatically learned from Web usage data by using web data mining techniques [2].

Due to large amount of "irrelevant information" in the web log, the original log file cannot be directly used in the web usage mining procedure. Therefore the pre-processing of web log file becomes imperative. To achieve appropriate mining on data, the design of a data e-learning web-house as supporting structure for future e-learning personalized systems has been proposed [17].

To provide learner with more personalized services, [20, 23, 25] Web usage mining can mine the server's log and the database to find the user's usage patterns. Data pre-processing is the required step to mine the web data. The survey on the preprocessing techniques has been done to identify the issues and how web usage mining pre-processing can be improved for pattern mining and analysis. Quality of pattern mining and pattern analysis is fully dependent on pre-processing step. The result of survey summarized the existing web log pre-processing techniques and concluded that Server log file is considered most authentic source for web usage mining. So it must be standardized and needs to be updated to capture user access data [24].

Research has introduced the Internet Search Advisor (ISA), a personalized, knowledge-driven search system that helps the user to find web information based on individual preferences. A data Miner is implemented to extract association rules and se- quential patterns based on an improved DHP algorithm that reduces the cost of the trim process [6].

With multi background student Environment, web based personalized learning recommender system provide learning recommendation to the students. The study has proposed a framework with two related technologies: one is a multi-attribute evaluation method to justify a student's need, and another is a fuzzy matching method to find suitable learning materials to best meet each student need [16]. Personalized search engine system has been proposed which could not only implicitly collect users' personal information and provide query expansion, but also provide the personal re-sort results. One of the researchers has proposed model to enhance personalized learning using learning style [7]. $\mathrm{He}$ had used two techniques for identifying learning patterns of learners and sequence of choosing learning resources: Association rules and Sequential patterns. Research work has presented a framework for mining, tracking, and validating evolving multifaceted user profiles on Web sites that have all the challenging aspects of real-life Web usage mining, including evolving user profiles and access patterns, dynamic Web pages, and external data describing ontology of the Web content [22],[26]. Personalized intelligent search engine based on web data mining involves not only data mining techniques but also artificial intelligence, pattern recognition, natural language retrieval, formal description and other related disciplines. So researchers of paper [10] depend on the development of these related disciplines to achieve real personalized information retrieval. In [4] new web search personalization approach that captures the user's interests and preferences in the form of concepts by mining search results and their clickthroughs.

Web recommender system has been proposed with a hybrid feedback mechanism that extracts a user's preference information and its associated Web-browsing behaviour [13], recommended learning objects are obtained by using a range of recommendation strategies based mainly on content based filtering and collaborative filtering approaches [19].

In paper [3] system is designed based upon the IEEE Learning Technology Systems Architecture (IEEE LTSA) architecture; a feedback extractor with fusion capability is introduced to combine multiple feedback measures to infer user preferences. The future work is suggested that learner's model should be comprised of three components: learner's profile, learner's knowledge and learner's educational preferences [18].

By considering and accepting research work and future suggestion given by the author, we have proposed an agent based personalized intelligent e-learning model.

\section{COMPARATIVE STUDY OF EXISTING ARCHITECTURE}

We have studied on existing models on personalization elearning used to study comparative analysis. Table 1 demonstrates comparative study based on the 5 parameters like Query Expansion, Learner's profile, Web log pre-processing, web knowledge discovery and opinion. Correct tick mark in table 1 suggests how the property of parameter has been achieved and guided to use all the stated parameters in the proposed model. 


\begin{tabular}{|c|c|c|c|c|c|}
\hline \multirow[b]{2}{*}{ Existing Architecture } & \multicolumn{5}{|c|}{ Parameters } \\
\hline & $\begin{array}{l}\text { Query Expan- } \\
\text { sion }\end{array}$ & Learner's Profile & $\begin{array}{l}\text { Web log pre- } \\
\text { processing }\end{array}$ & $\begin{array}{l}\text { Web knowledge } \\
\text { Discovery }\end{array}$ & Opinion \\
\hline $\begin{array}{l}\text { A Framework for Using Web Usage } \\
\text { Mining to Personalize E-learning }\end{array}$ & $\mathrm{X}$ & $\mathrm{X}$ & $\mathrm{X}$ & $\begin{array}{l}\text { To get learning } \\
\text { style, Association } \\
\text { rules and Sequential } \\
\text { patterns used }\end{array}$ & $\mathrm{X}$ \\
\hline $\begin{array}{l}\text { A Personalized e-Learning Material } \\
\text { recommender system }\end{array}$ & $\mathrm{X}$ & $\mathrm{X}$ & $\mathrm{X}$ & $\begin{array}{l}\text { By multi-attribute } \\
\text { evaluation and fuzzy } \\
\text { matching method }\end{array}$ & $\mathrm{X}$ \\
\hline $\begin{array}{l}\text { A Personalized E-Learning System } \\
\text { Based on User Profile Constructed } \\
\text { Using Information Fusion }\end{array}$ & $\mathrm{X}$ & $\begin{array}{l}\text { User Profiling as } \\
\text { an implicit feed- } \\
\text { back }\end{array}$ & $\mathrm{X}$ & $X$ & $\begin{array}{l}\text { Feedback } \\
\text { Extractor }\end{array}$ \\
\hline $\begin{array}{l}\text { An Adaptive e-Learning Recom- } \\
\text { mender Based on User's Web- } \\
\text { Browsing Behavior }\end{array}$ & $\mathrm{X}$ & $X$ & $\mathrm{X}$ & $\begin{array}{l}\text { Implicit feedback by } \\
\text { web-browsing beha- } \\
\text { vior }\end{array}$ & $\mathrm{X}$ \\
\hline $\begin{array}{l}\text { Automated Discovery, Categoriza- } \\
\text { tion and Retrieval of Personalized } \\
\text { Semantically enriched e-learning } \\
\text { resource }\end{array}$ & $\mathrm{X}$ & $\begin{array}{l}\text { Learner's Seman- } \\
\text { tic profile }\end{array}$ & $\mathrm{X}$ & $\mathrm{X}$ & $X$ \\
\hline $\begin{array}{l}\text { Automatic Recommendations for E- } \\
\text { Learning Personalization Based on } \\
\text { Web usage mining }\end{array}$ & $X$ & $X$ & $\begin{array}{c} \\
\text { pre-processes } \\
\text { data to build } \\
\text { learner and } \\
\text { content model }\end{array}$ & $\begin{array}{l}\text { Pattern discovery } \\
\text { using web usage } \\
\text { mining }\end{array}$ & $X$ \\
\hline $\begin{array}{l}\text { Design and Implementation of an } \\
\text { E-learning Model Based on WUM } \\
\text { Techniques }\end{array}$ & $\mathrm{X}$ & $X$ & $\begin{array}{l}\text { pre-processing } \\
\text { log data : Re- } \\
\text { quired step for } \\
\text { web usage Min- } \\
\text { ing }\end{array}$ & $\begin{array}{l}\text { Pattern discovery } \\
\text { using web usage } \\
\text { mining and analysis } \\
\text { pattern }\end{array}$ & $X$ \\
\hline $\begin{array}{l}\text { Improving Recall and Precision of } \\
\text { a Personalized Semantic Search } \\
\text { Engine for E-learning }\end{array}$ & $\mathrm{X}$ & $\mathrm{X}$ & $X$ & $\begin{array}{l}\text { Collecting ontology } \\
\text { based knowledge } \\
\text { and applying Se- } \\
\text { mantic web }\end{array}$ & $X$ \\
\hline $\begin{array}{l}\text { Personalized Search Based On } \\
\text { Learning User Click History }\end{array}$ & $\begin{array}{l}\text { QE By statis- } \\
\text { tical semantic } \\
\text { recommenda- } \\
\text { tion algorithm }\end{array}$ & $X$ & $\mathrm{X}$ & $\mathrm{X}$ & $X$ \\
\hline
\end{tabular}

Table 1 Comparative Study of Personalized E-learning Existing Architecture

All the disclosed architecture does not include all the parameters which are beneficial.
This gives an idea to merge all the benefits at one place in the proposed agent based personalized intelligent e-learning. 


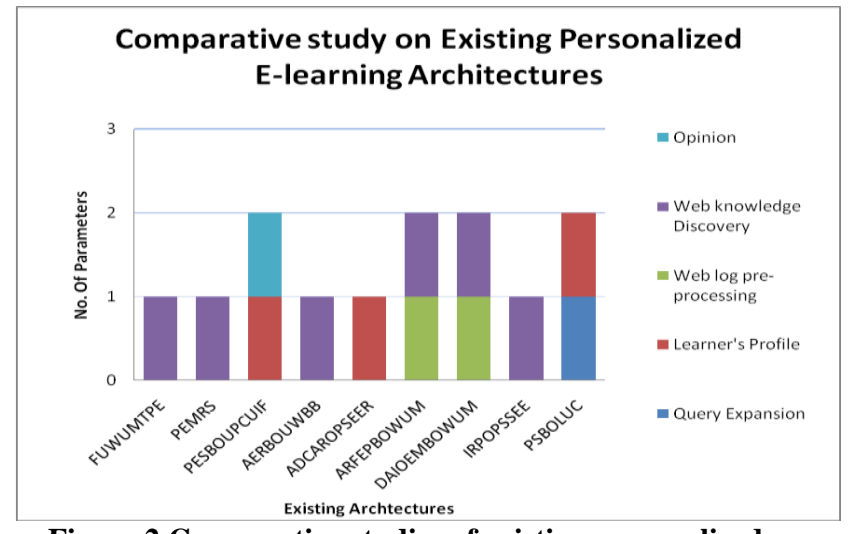

Figure 2 Comparative studies of existing personalized elearning architectures
$\mathrm{X}$-axis in Figure-2 presents all the existing architectures and $\mathrm{Y}$ axis presents no.of parameters employed. It gives an idea showcasing all the parameters are more or less used and web knowledge discovery is frequently utilized by existing models. All the stated 5 parameters are providing a significant role leading towards personalized e-learning model.

\section{METHODOLOGY}

The proposed model for personalized retrieval of pages through search engines is shown in figure 3. It provides general idea on multiple agent mechanism designed to achieve intelligent personalization. Agents include QE Agent, FTS Agent, MF Agent, WLP Agent, WKD Agent and Opinion Agent. Input Query provided by the learner is transferred to each agents in sequence to list down re-ranked Search Engine Results Page [SERP], Customized SERP and Personalized SERP.

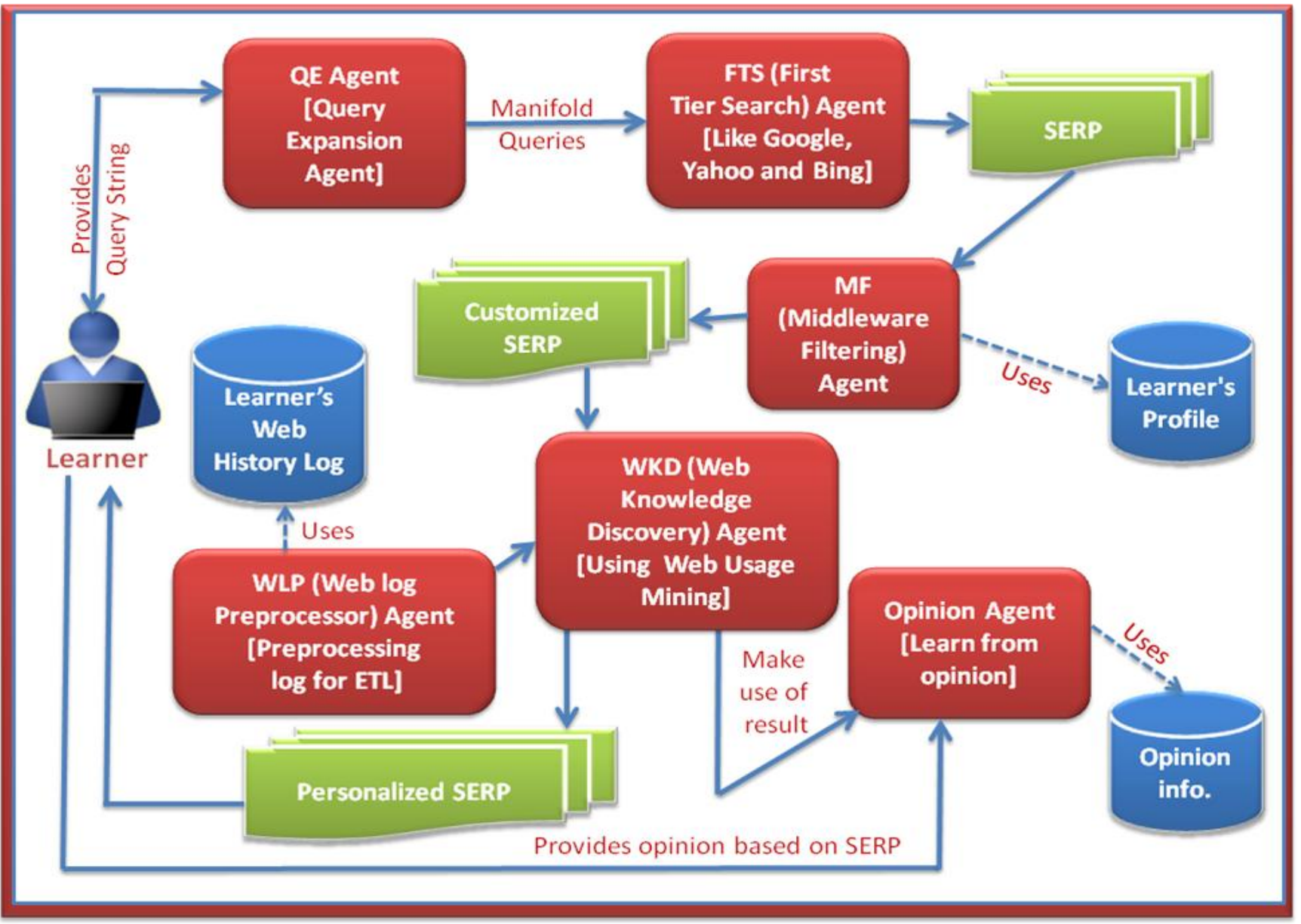

Figure-3 Agent Based Intelligent Personalized E-learning Search Engine Model

The working of each of the agents is discussed in the following section.

\subsection{QE Agent}

The purpose of Query Expansion Agent is to process user's Query and find out words which belong to same synset of the words contained in the user's query. E-dictionary would be used to realize the purpose. In addition, keyword research tools would be used to collect nearest meaning keywords. For example, Learner may input the Query "Java Tutorial". QE agent will generate nearest meaning using 
keyword research tools and would result to synset like java tutorial for beginners, learn java, simplifying java, java tutorial, sun java tutorial, java tutorial pdf, etc.

\subsection{FTS Agent}

The output of QE Agent is accepted as an input by First Tier search Agent to generate search Engine Result Pages (SERP) [11]. Google, yahoo and Bing are considered first tier or primary, search engines as they own most of the search engine's market share. These search engines usually polish the entire web, and in the process create very large index databases. This Indexed Database is used to retrieve result pages by the search engine. By means of search engine's Application programming Interface, FTS Agent will obtain an output for learner's Input Query.

\subsection{MF Agent}

Output of the FTS Agent is transmitted to the Middleware agent. The task assigned to MF agent is to re-rank on Search engine result pages leading to personalized retrieval of the pages. User profile will be built which would store user preferences, his/her interest, level of expertise, his preferred format of learning content, age of the learner, domain information etc. required for personalization. The information will be collected by user profiler to deliver personalized information using the collaborative filtering algorithm. MF Agent would then make use of user profiler to re-rank the pages, it uses learner's Profile.

\subsection{WLP Agent}

The function of Web Log pre-processor agent is to preprocess the web log providing it for the knowledge discovery task. To achieve appropriate mining on data, Web Log Pre-processor is required for the design of a web-house. Due to large amount of relevant and irrelevant transactional data exists in web log, pre-processing filters irrelevant data. Pre-processing techniques like extracting, cleaning, transforming, loading and integration would be surveyed and used for pre-processing. The output of this agent would be the data webhouse with the pre-processed web log mart.

\subsection{WKD Agent}

Web Knowledge Discovery which is also known as web mining consists of three categories: Web Usage Mining, Web Structure Mining and web Content Mining. Web Usage Mining plays major role for collecting information preferred and utilized by each individual leaner. Web Discovery Agent proposed in the architecture will accept output of web log pre-processing agent. Agent will study the browsing behaviour and pattern of learner like which websites have been visited, how much time has been spent on the content, sequence of the visited content etc. By means of deriving this type of information, web usage mining is used to associate, classify, correlate and cluster the learner's preferences. Proposed agent will use web house intelligently to learn user preferences by using web usage mining techniques. This has the potential to discover the knowledge regarding preference of the learner.

\subsection{Opinion Agent}

Explicit feedback has an added value to the expected intelligent outcome. Opinion Agent will use the learner's opinion to re-rank the personalized Search Engine Result Pages. Opinion mining techniques would be used for the same. This agent would also be expected to learn opinions of the learner from the social bookmarked facet.

\section{BENEFITS OF PROPOSED MODEL}

The model proposed in the paper would result into filtered but relevant material to a learner. This would reduce lots of effort and time of a learner wasted in searching the relevant content. This would in turn assist in retaining interest of a learner in his willingness to gain knowledge and learn rather than discouraging him in using World Wide Web for learning. Usage of Keyword Research Tools would result into search in widened but relevant horizon.

\section{CONCLUSION AND FUTURE WORK}

The focal point of the model was utilizing all the agents effectively to generate preferred, relevant and recommended personalized intelligent e-learning for the learner. The Model has good characteristics in providing preference to the learner with novel approach of finding nearby meaning of query and learner can also recommend result pages by their opinion. With this characteristic of the model ability of an individual will be increased to learn through personal experience and natural exploration. Our work would explore each and every agent to get efficient result of intelligent model. Future work also includes implementation and analysis for the same. At the first stage, First Tier Search Agent is used to collect the large amount of web pages on learner's Query but in future Web Crawler and Web Indexer Agent will be included to make first tier independent Agent.

\section{REFERENCES}

[1] I. Seher, A. G. (2007). A Personalized Query Expansion approach using Context. 2007 3rd IET International Conference on Intelligent Environments (pp. 383-390). Ulm : IEEE Xplore.

[2] Bamshad Mobasher, R. C. (2000). automatic personalization based on web usage mining. Communication of the ACM .

[3] Chang, X. L.-K. (1997). A Personalized E-Learning System Based on User Profile Constructed Using Information Fusion. Fab: content-based collaborative recommendation. CACM 1997 , (pp. Volume 40, no 9 ). Balabanovic, Shoham . 
[4] Cheqian Chen, K. L. (2010). Personalized search based on learning user click history. Cognitive Informatics (ICCI), 2010 9th IEEE International Conference on (pp. 490-495). Beijing : IEEE Explore.

[5] Fang Liu, C. Y. (2002). Personalized Web Search by Mapping User Queries to Categories. Proceeding CIKM '02 Proceedings of the eleventh international conference on Information and knowledge management. Newyork, USA: ACM.

[6] George T. Wang, F. X. (2002). Web Search with Personalization and Knowledge. Proceedings of the IEEE Fourth International Symposium on Multimedia Software Engineering (MSE’02) (p. 2002114351/02). IEEE.

[7] Hafidh Ba-Omar, I. P. (2007). A Framework for Using Web Usage Mining to Personalise E-learning. Seventh IEEE International Conference on Advanced Learning Technologies (ICALT 2007) (pp. 937-938). Japan: IEEE.

[8] Hai-Jew, S. (2008). Scaffolding Discovery Learning Spaces. MERLOT Journal of Online Learning and Teaching, (pp. 533-549). USA.

[9] Hisham Al-Mubaid, P. C. (2005). Context-Based Similar Words Detection and Its Application in Specialized Search Engines. Proceeding IUI '05 Proceedings of the 10th international conference on Intelligent user interfaces (pp. ISBN: 1-58113-894-6 Order Number: 608050 doi>10.1145/1040830.1040890). New York, NY, USA : ACM New York, NY, USA @2005.

[10] Hong Zhang, Y. M. (2009). Personalized Intelligent Search Engine Based on Web Data Mining. Proceedings of the 2009 International Workshop on Information Security and Application (IWISA 2009) (pp. ISBN 978-952-5726-06-0). China: 2009 ACADEMY PUBLISHER AP-PROC-CS-09CN004.

[11] Search Engine Results Page (SERP), Retrieved from http://en.wikipedia.org/wiki/:

http://en.wikipedia.org/wiki/Search_engine_results_pa ge

[12] Jerkovic, J. I. (2009). SEO Warrior. O'Reilly Media, Inc.

[13] Kosuke Takano, K. F. (2010). An Adaptive eLearning Recommender Based on User's WebBrowsing Behavior. 2010 International Conference on P2P, Parallel, Grid, Cloud and Internet Computing (pp. 978-0-7695-4237-9/10). IEEE.

[14] Leung, K.-T., Lee, D., \& Lee, W.-C. (2010). Personalized Web search with location preferences. Data Engineering (ICDE), 2010 IEEE 26th International Conference (pp. 702-712). China: IEEE Explore.

[15] Literacy Rate in India. (2010 ). Retrieved from http://india.gov.in/: http://india.gov.in/knowindia/literacy.php

[16] Lu, J. (2004). A Personalized e-Learning Material Recommended System. Proceedings of the 2nd
International Conference on Information Technology for Application (ICITA 2004). ICITA.

[17] Marta Zorrilla, S. M. (2005). Data Webhouse to support web intelligence ine-learning environments. Granular Computing, 2005 IEEE International Conference (pp. 722 - 727 Vol. 2). Spain: IEEE Explore.

[18] Mohamed Koutheaïr Khribi, M. J. (2008). Automatic Recommendations for E-Learning Personalization Based on Web Usage Mining Techniques and Information Retrieval. Proceeding ICALT '08 Proceedings of the 2008 Eighth IEEE International Conference on Advanced Learning Technologies (pp. 30-42). Washington, DC, USA : EEE Computer Society.

[19] Nasraoui, L. Z. (2009). Automated Discovery, Categorization and Retrieval of Personalized Semantically Enriched E-learning Resources. 2009 IEEE International Conference on Semantic Computing (pp. 978-0-7695-3800-6/09). IEEE.

[20] Nasraoui, O. (2006). Seventh International Workshop on Knowledge Discovery on the Web. Springer.

[21] Olfa Nasraoui, L. Z. (2010). Improving Recall and Precision of a Personalized Semantic Search Engine for E-learning. 2010 Fourth International Conference on Digital Society. USA: IEEE.

[22] Olfa Nasraoui, M. S. (2008). A Web Usage Mining Framework for Mining Evolving User Profiles in Dynamic Web Sites. IEEE TRANSACTIONS ON KNOWLEDGE AND DATA ENGINEERING, VOL. 20, NO. 2, FEBRUARY 2008 (pp. 1041-4347/08). IEEE.

[23] R. Cooley, B. M. (2002). Web Mining: Information and Pattern Discovery on the World Wide Web. Tools with Artificial Intelligence, 1997. Proceedings., Ninth IEEE International Conference (pp. 558-567). Newport Beach, CA, USA: IEEE.

[24] Tasawar Hussain, D. S. (2010). Web usage mining: A survey on preprocessing of web log file. Information and Emerging Technologies (ICIET), 2010 International Conference (pp. 1-6). Karachi : IEEE Explore.

[25] Xinjin Li, S. Z. (2010). Application of Web Usage Mining in e-learning Platform. 2010 International Conference on E-Business and E-Government (p. DOI 10.1109/ICEE.2010.353). IEEE.

[26] Xue Sun, W. Z. (2009). Design and Implementation of an E-learning Model Based on WUM Techniques. 2009 International Conference on E-Learning, EBusiness, Enterprise Information Systems, and EGovernment (pp. 978-0-7695-3907-2/09). IEEE. 